\title{
POLICY The problems of smaller, rural and remote hospitals: Separating facts from fiction
}

\author{
Authors: Louella Vaughan ${ }^{A}$ and Nigel Edwards ${ }^{B}$
}

Smaller hospitals internationally are under threat. The narratives around the closure of smaller hospitals, regardless of size and location, are all constructed around three common problems - cost, quality and workforce. The literature is reviewed, demonstrating that there is little hard evidence to support the contention that hospital merger/closure solves these problems. The disbenefits of mergers and closures, including loss of resources, increased pressure on neighbouring organisations, shifting risk from the healthcare system to patients and their families, and the threat hospital closure represents to communities, are explored. Alternative structures, policies and funding mechanisms, based on the evidence, are urgently needed to support smaller hospitals in the UK and elsewhere.

KEYWORDS: Rural hospital economics, rural hospital organisation, mergers, health services research

\section{Introduction}

Smaller hospitals are internationally under threat. Over the past decade, attempts to rationalise care have seen services, particularly obstetrics and surgery, stripped out of organisations in very rural locations in Australia, USA and Canada. ${ }^{1-4}$ The pace and scale of change has been accelerating over the last few years, spreading to include provincial hospitals in more densely populated countries. In the last 12 months, a national report has called for the closure of half of all hospitals in Germany, while doctors and nurses in France have staged months of protests over the demise of emergency and community services in smaller towns and rural areas. ${ }^{5,6} \mathrm{~A}$ quarter of all smaller hospitals in the USA are now thought to be on the brink of closure. ${ }^{7}$ Although The NHS Long Term Plan for England pledged support for smaller hospitals, many sustainability and transformation partnerships (STPs) are predicated on major reconfigurations of services that would result in either the substantial downgrading or closure of smaller acute sites. ${ }^{8-10}$

This would all suggest that smaller hospitals matter little in the delivery of healthcare at national level, with larger organisations providing the dominant share of secondary and tertiary care. In fact, large hospitals with a comprehensive range of services are

Authors: ${ }^{\text {A }}$ senior clinical fellow, The Nuffield Trust, London, UK; ${ }^{B}$ chief executive officer, The Nuffield Trust, London, UK the exception rather than the norm, with most hospitals in Europe, North America and the Antipodes having only 100-250 beds. ${ }^{11}$ In the UK, nearly half the population is served by organisations deemed to be 'smaller.12 Moreover, smaller hospitals tend to be located in more rural and remote locations with higher levels of deprivation and where the local populations are older, more vulnerable and have more complex, comorbid disease.

It is critical to note in any discussion looking internationally at smaller hospitals, that what constitutes 'smaller', 'rural' and 'remote' is highly contingent on context. Critical access hospitals in the USA, for example, are defined as having no more than 25 beds, an average length of stay of under 96 hours and located more than 35 miles from the next closest hospital. ${ }^{13}$ By contrast, smaller hospitals in England are defined as having an annual operating revenue of less than $£ 300$ million, which results in that the average smaller hospital has 480 beds, with one 800 -bedded hospital fitting this definition. ${ }^{12}$ This means that what is regarded as 'small' in the UK would be considered as a medium or even large hospital elsewhere in the world. Some jurisdictions have specific legislation and/or policies to support rural healthcare, as well as differential models of funding predicated on hospital size and/or location. ${ }^{14}$ This used to be the case in England, with the Bonham-Carter report focusing on the establishment of district general hospitals (DGHs) to meet the needs of local populations. ${ }^{15}$ The distinction, however, between DGHs and tertiary hospitals was effectively erased with the Health and Social Care Act of 2003, which made foundation status the defining criteria for funding and policy purposes. ${ }^{16}$

The narratives constructed around the closure of smaller hospitals, regardless of their size and location, all share common features. Firstly, they are almost universally framed around three themes - cost, quality and workforce. Moreover, they all imply that their larger, urban and more specialist counterparts should effectively take over the work of smaller hospitals. In this article, we will explore the evidence for each of narratives. Where possible, the evidence relevant to NHS will be given the most weight. Where such local evidence is lacking, we will turn to the international literature.

\section{The problem of cost}

The potential for cost saving and improvements in efficiency of healthcare delivery is, perhaps, the most common reason cited for the closure of smaller hospitals or their vertical or horizontal integration into other organisations. The underlying rationale is that there are certain fixed costs attached to 'keeping the lights 
on' in any hospital, making the cost per patient in lower volume organisations inherently more expensive. ${ }^{17}$ Conversely, larger hospitals are able to achieve economies of scale and are more competitive in systems where payment is funded by results. This has led to a commonly held notion that there is a minimum viable hospital size. ${ }^{18}$

These were the chief reasons underpinning the introduction of competition on the supply side in the NHS in 1990 and the later mergers of poorly performing organisation with their neighbours under the Blair government. Both sets of policies sought to create economies of scale, thereby bringing about cost savings and major efficiency gains. ${ }^{19,20}$

Explorations of the closure and merger of organisations internationally and the impact on cost have since concluded that they rarely result in lower costs and fewer, if any efficiencies. ${ }^{21}$ Studies of vertical and horizontal integration have similarly failed to find any genuine, sustained benefits and there is strong signal that integration may, in fact, reduce the quality of care provided to patients. ${ }^{22,23}$ Propper's study of the closure of 112 hospitals in the period 1997-2006 in the UK concluded that mergers had no impact across a broad range of outcomes, including financial performance, productivity, waiting times and clinical quality. In fact, there was little evidence of any type of gain and the result was, instead, a reduction in clinical capacity and an increase in financial deficits. ${ }^{20}$

Parallel to this, international researchers looking at optimum hospital size have come to the conclusion that diseconomies of scale for hospitals exist below 200 beds and above 600 beds. ${ }^{21,24-26}$

It had been suggested that closure of hospitals may result in cost savings at system level by forcing populations impacted by closure to seek alternative, cheaper sources of healthcare. While there was some signal for this in Propper's work, a more recent study by Knowles of the closure of five emergency departments between 2009 and 2011 found that there was no overall change in the usage of emergency hospital services - patients simply travelled further to the next hospital. ${ }^{20,27}$ Although no economic analysis was performed, the increased usage of ambulances for conveyance implies that the closures likely increased, rather than reduced, system level costs.

While it may be broadly true that the 'fixed costs' dominate the economics of hospital care, the financial viability of smaller organisations appears to be determined by a broader range of factors, including the capital costs of replacing poor infrastructure, the servicing of related debt, the alignment of physicians to the priorities of the hospital, the quality of leadership and management, and the reputation of the organisation. ${ }^{28,29}$ More importantly, it has been found that payment systems based on fee-for-service do tend to systematically disadvantage smaller hospitals, especially so in markets with a single dominant payer. This, however, has less to do with lack of cost effectiveness of care, but rather is a by-product of payment systems. ${ }^{29,30}$ This effect is exaggerated in the NHS, where funding structures tilt payments towards urban areas, based on historical precedence and somewhat arbitrary judgements. ${ }^{31}$

The only area where costs are consistently higher for smaller hospitals are expenses related to the medical and nursing workforce. Most smaller hospitals suffer from chronic workforce shortages (see below), making them reliant on expensive locums, thereby driving up the staff costs. Successive attempts to cap locum spend, although they have reduced the total bill for services, have still not succeeded, with record amounts being spent to cover critical gaps in service. ${ }^{32}$

\section{The problem of quality}

The prevailing perception is that the quality of care at smaller hospitals is substantially less good than that provided in larger organisations. This stems from investigations into three overlapping areas that are effectively synonymous with care in bigger institutions - specialisation, centralisation and volume. There is undeniably a corpus of literature which has identified substantial benefits from each of these aspects of care. The evidence is clear that care by specialists is substantially better for a range of complex surgical interventions, such as cardiovascular procedures and cancer resection, and for specific medical conditions such as myocardial infarction, HIV, complex musculoskeletal and infectious diseases, variously reducing mortality, morbidity and costs in comparison with generalist care. $^{33-37}$ Similarly, there is evidence that centralisation and higher volumes (at both clinician and organisational levels) for the care of conditions that require either time-sensitive care and/or highly technical skills can lead to better outcomes. ${ }^{38-41}$

However, there is no evidence that care at smaller hospitals is, per se, any poorer overall than care in larger ones. Monitor's study of England's 75 smaller hospitals concluded that there was no evidence to support the contention that their care, as a group, was any worse than that delivered in hospitals with more than 700 beds. ${ }^{12}$ Studies of specific critical services in England, such as emergency general surgery, intensive care and emergency medicine, have also failed to find associations between hospital size and outcomes. ${ }^{42-45}$

More generally, the research on the benefits of specialisation, centralisation and high volumes is fraught with methodological problems. Systematic reviews of specialist versus generalist care found that studies favouring specialist care tended to fail to consider key confounding factors and that there was insufficient evidence to conclude which type of care was better. ${ }^{46,47}$ Further, they warned of the perils of interpreting the more rapid of adoption of knowledge and interventions into practice as evidence of 'better care', when specialist care was frequently associated with more interventions, higher costs and little evidence of better outcomes. ${ }^{48}$ More importantly, variations in quality of care between individual generalists and between individual specialists were often found to be larger than the variations between generalists and specialists as groups. ${ }^{46}$

Relationships between the experience of individual providers, provider volume and hospital volume have proven difficult to unpick, with the suggestion that the characteristics of individual providers (volume and experience) may be more important than the nature of the hospital in which they work. ${ }^{49,50}$ Nally's national study of outcomes for emergency abdominal surgery in Ireland, for example, found that although high-volume teams in highvolume hospitals performed best on all metrics, high-volume teams in low-volume hospitals outperformed all other teams on almost all metrics. The worst outcomes were for low-volume teams in high-volume hospitals. ${ }^{51}$ It also appears that the type of intervention is also important, with a strong suggestion that volume is more important for complex interventions, while less challenging surgery and obstetric interventions can be safely provided by generalists in lower-volume settings. ${ }^{52-54}$ 
Studies on volume effects from the USA also need to be interpreted with caution, as the patient numbers per clinician are substantially lower, making translation into the UK context problematic. A large recent study, for example, exploring the relationship between physician age, patient volume and outcomes for unselected patients aged over 65 years with medical conditions found that younger clinicians were associated with lower patient mortality than their older colleagues, a distinction that disappeared among high-volume clinicians. ${ }^{55}$ 'High volume', however, was defined as $>201$ cases per year. As the average clinician participating in the unselected take in the UK sees 25-35 patient per on-call shift, this makes virtually all acute and general physicians in the UK 'high volume', rendering the study results inapplicable universally.

Recent efforts in England to realise the potential benefits of centralising and increasing the volume of services have produced mixed results. Although the formation of the stroke network in London resulted in significant improvements in mortality and length of stay, similar outcomes have been slow to materialise elsewhere. ${ }^{56}$ Similarly, although the development of the English trauma network has led to improvements in processes of care and case-mix adjusted mortality, there has been an increased burden on receiving hospitals with no evidence of impact on adjusted mortality or uniform benefit for all patient groups. ${ }^{57,58}$

It is also important to note that the work evidenced to be better done by a specialist constitutes a sliver of the total work of a hospital. Myocardial infarction, stroke and trauma represent $1 \%$ of the total presentations to emergency departments, while the 1.3 million general surgical procedures dwarfs the $\sim 50,000$ vascular interventions performed annually in England. ${ }^{59-61}$ Recent work by the Nuffield Trust found that up to $85 \%$ of all medical admissions to smaller hospitals could be considered be to amenable to generalist care. ${ }^{11}$

Overall, this suggests that while certain highly technical services should and ought to be provided in larger, specialist centres, the majority of patients can be safely cared for in smaller organisations.

\section{The problem of workforce}

Smaller hospitals are challenged world-wide by problems with workforce. Not only do smaller organisations have difficulties in attracting suitably qualified professionals, with many rural and costal locations being in decline and/or socially deprived, but they have more difficulties with retention. ${ }^{62}$ Recent work by the Nuffield Trust found that $90 \%$ of smaller hospitals had problematic gaps in their middle grade rosters and that the majority were reliant on consultant locums to support their acute and emergency services. ${ }^{11}$ This reliance on locums drives up financial costs and contributes to perceptions around lack of safety and quality.

Superficially, larger metropolitan hospitals appear to offer prestige, financial benefits including private practice, shorter working hours, and cultural and social opportunities, set against the longer working hours, lower incomes, and the professional and social isolation of the jobbing consultant in a smaller hospital. ${ }^{63,64}$ This, combined with the major workforce crisis in the UK when $\sim 50 \%$ of advertised jobs in acute specialties are going unfilled, makes the workforce problems seem intractable and further hospital closures and mergers inevitable. ${ }^{65,66}$

Any sensible discussion on the problems of workforce needs to acknowledge that models of staffing are driven predominantly by historical precedent and contractual obligations, rather than by either patient need or a nuanced reading of the literature on the relationships between staffing and outcomes. ${ }^{11}$ This is particularly problematic in the UK, where guidelines for safe medical staffing have been developed for each individual specialty, leading to the insistence on a 'minimum of one of each at all times' model of staffing hospitals. While this may be entirely appropriate for larger, busier organisations, this may not be uniformly necessary. Moreover, this way of staffing, when combined with the restrictions of the European Working Time Directive, means that departments which in other jurisdictions could be maintained with two to five consultants require a minimum of nine in the UK, thereby creating artificial workforce shortages. ${ }^{11,66}$ Guidelines that were constructed as being aspirational have been interpreted as mandatory, not only by hospitals themselves, but by external bodies, meaning that these artificial shortfalls in staffing are viewed as threats to patient safety, despite organisations otherwise demonstrating good outcomes. ${ }^{67}$ It is telling that the Faculty of Intensive Care Medicine has recently stepped back from its original guidance on staffing and acknowledged that while all patients should receive uniformly excellent care, its prior insistence on 24/7 intensivist-only staffing had left units in difficulty. ${ }^{68}$

The evidence suggests that workforce solutions require a threepronged approach. ${ }^{69-71}$ The first and most immediate of these is for individual hospitals struggling with shortages to pay attention to their offer. 'Hygiene' factors play a critical role in the morale of staff and their retention. At their most basic level, attention to hygiene factors means giving staff the basic tools to their job effectively, such as functional computers and other IT systems, office space and other facilities, such as car parking. Beyond this, improvements in cultural and social factors, such as fostering good relationships within teams and managers, equitable and transparent distribution of work, and access to educational and professional opportunities are highly valued by doctors. Although doctors are less motivated by financial considerations, local solutions to the current pensions crisis are likely to contribute to retention. Many of these solutions do require expenditure and are superficially unattractive in times of fiscal constraint. However, the literature suggests that investment in hygiene factors tends to produce quick returns and substantial longer-term savings.

Smaller hospitals also need to rethink their service models and shift from traditional models arranged around 'departmental' blocks and professional boundaries. ${ }^{11,69}$ A deeper and more nuanced understanding of exactly what are the needs of the local community would allow the development of interdisciplinary and multiprofessional teams based around skills, expertise and experience. Upskilling of existing staff and enabling them operate at the 'top of their licence' makes better use of resources and creates jobs that are more interesting and attractive. ${ }^{72}$ Smaller hospitals will also need to be better integrated into networks of specialist care, so that the management of the sickest patients becomes frictionless in terms of accessing appropriate advice and arranging transfer where necessary.

Such a reconsideration of better matching staffing with patient need is most urgently needed in the out-of-hours context.

Pressures at night are predominantly caused by insufficient staff to meet the evening peak of demand, which subsequently increases the staff needed at night. ${ }^{73,74}$ Ensuring that patterns of staffing match demand would mean that hospitals could shift to the use of single, unified hospital at night teams to cover all areas. The 
arrangements for consultant on call for interventional specialties, such as gastroenterology and surgery, and as well as any other high-frequency / low-intensity on-call services should also be scrutinised, with a consideration of whether alternative funding mechanisms (such as locally negotiated payments for call out) or networked 'treat-and-transfer' models are viable alternatives.

The discussion so far has rested on retention and better use of existing staff. Longer-term solutions stem from understanding what underpins the choice of place to practice. Choices of location of practice are complex and determined by constellations of factors, including coming from a rural background, exposure to non-metropolitan settings during medical school and higher training, the availability of financial incentives, and support for families. ${ }^{75,76}$ Internationally, many of these issues have been addressed through preferential selection to medical school, changes to undergraduate and postgraduate training, the founding of rural medical schools, the creation of rural generalist colleges, and local and federal bursary and relocation schemes, with evidence of sustained benefit. ${ }^{77-79}$

The UK has lagged behind other countries in creating structures to underpin the non-urban workforce, but this is beginning to change. While not explicitly tagged as 'rural', the five new medical schools being created as part of the major expansion in workforce are all in non-metropolitan areas and are expected to have a more generalist focus. ${ }^{80}$ Part of the remit of the newly launched Medical Education Reform Programme is to review the distribution of trainees across England and to ensure a better geographical balance of trainees in the future and boosting the middle grade workforce in smaller hospitals. ${ }^{81}$ The Targeted Enhanced Recruitment Scheme has been highly successful in increasing the number of general practitioner trainees moving to under-doctored locations in return for a one-off 'golden handshake'. ${ }^{82}$

This suggests that closing hospitals on the pretext of inadequate staffing is a short-term, nihilistic solution to a problem that, although urgent, is not without alternative solutions.

\section{The unrecognised problems of closure}

There is a natural assumption on the part of policy and decision makers that the promise of better care elsewhere, such as larger hospitals or in alternative community settings, will override any dismay that communities might feel about the closure of their local hospital. In truth, communities invariably resist hospital closures, often successfully. ${ }^{83}$ Moreover, while doctors and managers frame arguments about services in terms of quality, safety, cost and efficiency, patients and other community stakeholders have entirely different sets of concerns. ${ }^{83,84}$ Instead, they view local access to hospital services as a 'self-evident good', and consider that most problems could be solved with appropriate resources. They are clear about the burdens imposed by increased travel time and isolation from friends and family. The role of the hospital in the community is also critical - not only were hospitals frequently the largest employer in the area, but they were imbued with substantial political and symbolic power of the importance of the area in the wider context. These and other arguments about the disbenefits of hospital closure are rarely discussed in the medical context and we shall touch on the evidence regarding them here.

There have been methodological difficulties in quantifying the impact of smaller hospitals at population level. Early studies had suggested that the longer-term impacts of closure were negligible. ${ }^{85,86}$ By contrast, more recent studies have found that hospital closures or mergers are rarely accompanied by increases in capacity at neighbouring organisations. This, in turn, leads to overcrowding and stretched services, with worsening of patient outcomes, for resource-intensive services such as emergency medicine and obstetrics. ${ }^{87,88}$ Two Harvard studies found that closure of rural hospitals resulted in a $3 \%$ rise in 30-day mortality for patients overall and a $5 \%$ rise in 1-year mortality for time-sensitive conditions; there was no evidence of any cost savings from closures. ${ }^{89,90}$ These findings were mirrored in a study of hospital closures in California, which found an increase in overall mortality, with changes in mortality differing by diagnostic condition. ${ }^{91}$ Mirroring these findings in England, Knowles found that hospital closures produced a trend towards an increase in mortality at population level, with evidence of increased pressure on neighbouring organisations. ${ }^{27}$

Merger and closure of hospitals is often portrayed as the solution to the organisational and cultural problems of under-performing organisations. ${ }^{92}$ Instead, the literature suggests that the 'system shock', that is the instability and uncertainty created even by the discussion of major reorganisation change, can inhibit other processes within hospitals, often resulting in organisational paralysis, and failure of other improvement processes. ${ }^{93,94}$ Postmerger integration is rarely successful, with leaders lacking "the necessary understanding and appreciation of the differences in cultures, values and goals of the existing facilities, ${ }^{95,96}$ As noted by Collins, as merger is usually 'a last ditch response to failure', making it hardly surprising that reconfiguration itself is a major risk factor for ongoing poor performance. ${ }^{97}$

The costs attached to the process of reconfiguration are also substantially underestimated and are rarely included in any preliminary financial analysis. An estimated $£ 2$ billion was allocated to 12 mergers occurring between 2010 and 2015. Most of this funding, however, was not related to achieving the mergers, but rather to writing down historic debts and deficits and capital spend to improve existing facilities. ${ }^{97}$ More recently, the planned changes to north-west London were eventually shelved after 9 years and an estimated spend of $€ 80$ million. ${ }^{98}$

The public's concerns about the increased isolation of patients being cared for at a distance from home are real. Rural and remote areas frequently suffer from poor public transport, making it difficult, if not impossible, for relatives and friends to visit and provide support. ${ }^{99}$ As in the UK transfer to a larger organisation often means crossing into territory belonging to another local authority or clinical commissioning group, this can make discharge more complex to facilitate and lead to delayed transfers of care. Certain rural areas also have profound problems in recruiting staff to provide social care, further impeding discharge from hospital. ${ }^{100}$ Networks of care can pose particular issues, with patients bypassing the nearest hospital to go to specialist centres even further away. Stroke presents genuine challenges, as $30-50 \%$ of patients transferred to a stroke centre will not actually have a stroke, but rather a stroke mimic, leaving patients who could be cared for closer to home stranded some distance away. ${ }^{101}$

The research suggests then, that rather than the closure of smaller hospitals resulting in better care at population level, it can result in overcrowding in remaining organisations, with evidence of increases in mortality and cost, and significant disbenefit to patients. This has led some to conclude that hospital or service closures do not remove risk, but rather transfer the risk from the healthcare system to patients and their families. ${ }^{102,103}$ The process 
of merger and/or closure destabilises organisations and rather than driving improvement, can inhibit or even worsen future performance.

\section{Smaller hospitals and social justice}

Communities in rural and remote places are almost invariably organised around a few key institutions and organisations hospitals, educational organisations, public services and, much less so in the UK, the church. These have been conceptualised as 'anchor institutions', which point to the pivotal roles and responsibilities that these organisations have in the economic and social fabric of the communities in which they sit. ${ }^{104}$

Of these, hospitals are frequently the most important. They are often the biggest local employers and support many other business and providers on a contractual basis. While in the UK, general practice is frequently constructed as the pivotal point for population health, the reality is that hospitals provide a 'centre of gravity' for health economies and frequently lead the local 'mission' for the provision of care, if in less coordinated fashion than happens elsewhere. ${ }^{105}$

Research into the closure of smaller hospitals, especially those in rural and remote areas, has found major impacts on local communities, with evidence of a cascade effect. ${ }^{106-108}$ Hospital closure tends to trigger an exodus of local general practitioners, allied health and other community-based staff, following increases in the burden of work for those remaining. Low-skilled workers who lose their hospital jobs frequently have difficulty in finding alternatives, further stretching sparse local resources. Lack of health services makes it unlikely that people, especially those with younger families, will relocate to the town and will be a factor in others leaving, especially those with chronic health problems. Hospital closure can rapidly lead to whole towns becoming unviable, resulting in social isolation and deprivation for those who stay.

Hospitals also stand as symbols that communities matter in the wider political and social context. Closing hospitals is frequently interpreted by locals as a clear statement that their needs count for less than their urban counterparts and is met with increasing feelings of alienation from the political process. ${ }^{84}$ Jurisdictions with policies that support smaller, rural and remote hospitals almost universally cite the importance of equity and social justice in the provision of healthcare to all citizens and acknowledge the harms created by its lack. ${ }^{109}$

\section{Conclusion}

This brief overview of the literature demonstrates that there is little or no evidence to support the closure of smaller hospitals in the UK on the grounds of finances, quality or staffing. Moreover, there is substantial evidence that hospital closures cause direct harm to patients, increase the burdens on the system and contribute to deprivation and health inequalities. Rather than hospital mergers and closures being the solution to the problems within the NHS, we would instead contend that the previous rounds of mergers and closures have played a major role in creating the current healthcare landscape, one plagued by too few resources, financial constraint and organisational problems. 'Smaller' hospitals in the UK are not small by any international measure and there are few, if any, economies of scale to be gained. More of the same is not the answer. Facts, not fiction, need to underpin appropriate structures, policies and funding mechanisms that will genuinely allow high-quality care to be delivered to patients closer to their homes.

\section{Acknowledgements}

The authors would like to acknowledge all the collaborators, investigators and contributors to the Nuffield Trust's work on smaller hospitals over the past years, who have substantially shaped our thinking about the importance of smaller hospitals. We are also grateful to William Palmer, John Appleby and Jonathan Spencer, colleagues at the Nuffield Trust, whose economic analysis of smaller hospitals in England underpins portions of this work.

\section{References}

1 Queensland Health. Rural maternity taskforce report. Brisbane: Queensland Health, 2019.

2 Hung P, Kozhimannil KB, Casey MM, Moscovice IS. Why are obstetric units in rural hospitals closing their doors? Health Serv Res 2016:51:1546-60.

3 Angle P, Kurtz Landy C, Murthy Y, Cino P. Key issues and barriers to obstetrical anaesthesia care in Ontario community hospitals with fewer than 2,000 deliveries annually. Can J Anaesth 2009;56:667-77.

4 Humber N, Frecker T. Delivery models of rural surgical services in British Columbia (1996-2005): are general practitioner-surgeons still part of the picture? Can J Surg 2008;51:173-8.

5 Albrecht M, Loos S, Zich K. Zukunftsfähige Krankenhausversorgung Simulation und Analyse einer Neustrukturierung der Krankenhausversorgung am Beispiel einer Versorgungsregion in Nordrhein-Westfalen. Gütersloh: Bertelsmann Stiftung, 2019. www.bertelsmann-stiftung.de/fileadmin/files/BSt/Publikationen/ GrauePublikationen/VV_Bericht_KH-Landschaft_final.pdf

6 Chrisafis A. French medics warn health service is on brink of collapse. The Guardian 2019. www.theguardian.com/world/2019/ jun/11/french-medics-health-service-collapse-doctors-nursesprotest-outside-french-health-ministry-strikes

7 Kacik A. Nearly a quarter of rural hospital are on the brink of closure. Modern Healthcare 2019. www.modernhealthcare.com/ article/20190220/NEWS/190229999/nearly-a-quarter-of-ruralhospitals-are-on-the-brink-of-closure

8 NHS England. The NHS Long Term Plan. London: NHS, 2019.

9 Ham C, Alderwick H, Edwards N, Gainsbury S. Sustainability and transformation plans in London: An independent analysis of the October 2016 STPs. London: The King's Fund, 2017.

10 Boyle S, Lister J, Steer R. Sustainability and transformation plans: how serious are the proposals? A critical review. London: Southbank University, 2017.

11 Vaughan L, Edward N, Imison C, Collins B. Rethinking acute medical care in smaller hospitals. London: Nuffield Trust, 2018.

12 Monitor. Facing the future: smaller acute providers. London: Monitor, 2014

13 Centers for Medicare \& Medicaid Services (CMS), Department of Health and Human Services. Medicare and Medicaid programs; reform of hospital and critical access hospital conditions of participation. Final rule. Fed Regist 2012;77:29034-76.

14 Rechel B, Džakula A, Duran A et al. Hospitals in rural or remote areas: An exploratory review of policies in 8 high-income countries. Health Policy 2016;120:758-69.

15 Central Health Services Council. The functions of a district general hospital. Bonham-Carter report. London: Department of Health and Social Security, 1969.

16 Health and Social Care Act 2012: 2012 chapter 7. The National Archives, 2012 www.legislation.gov.uk/ukpga/2012/7/contents/ enacted 
17 Roberts RR, Frutos PW, Ciavarella GG et al. Distribution of variable vs fixed costs of hospital care. JAMA 1999;281:644-9.

18 Edwards N. Hospitals: is bigger better? London: The King's Fund, 2013. www.kingsfund.org.uk/publications/articles/hospitals-biggerbetter

19 Goddard M, Ferguson B. Mergers in the NHS Made in heaven or marriages of convenience? London: Nuffield Trust, 1997.

20 Gaynor M, Laudicella M, Propper C. Can governments do it better? Merger mania and hospital outcomes in the English NHS. NBER working paper no 17608. Cambridge: National Bureau of Economic Research, 2011. www.nber.org/papers/w17608

21 Giancotti M, Guglielmo A, Mauro M. Efficiency and optimal size of hospitals: Results of a systematic search. PLOS ONE 2017;12:e0174533.

22 Burns LR, Goldsmith JC, Sen A. Horizontal and vertical integration of physicians: A tale of two tails. Annual review of health care management: Revisiting the evolution of health systems organization (advances in health care management, vol 15). Blingley: Emerald Group Publishing, 2014.

23 Gaynor M. Examining the impact of health care consolidation. Statement before the Committee on Energy and Commerce Oversight and Investigations Subcommittee, US House of Representatives. US House of Representatives Document Repository, 2018. https://docs. house.gov/meetings/IF/IF02/20180214/106855/HHRG-115-IF02Wstate-GaynorM-20180214.pdf

24 Nuffield Institute for Health, NHS Centre for Reviews and Dissemination. Hospital volume and health care outcomes, costs and patient access. Effective Health Care 1996;2:1-16. www.york. ac.uk/media/crd/ehc28.pdf

25 Campbell T. Economies of scale in Irish hospitals. Dublin: Irish Economic and Evaluation Service, 2016.

26 Posnett ]. Are bigger hospitals better? In: McKee M, Healy ] (eds). Hospitals in a changing Europe. Buckingham: Open University Press, 2002:100-18.

27 Knowles E, Shephard N, Stone T et al. Closing five emergency departments in England between 2009 and 2011: the closED controlled interrupted time-series analysis. Health Services and Delivery Research, no 6.27. Southampton: NIHR Journals Library, 2018.

287 factors to assess the sustainability of a hospital: assessing a hospital's viability, its financial situation and the severity of the threats it faces. Becker's Hospital Review 2010. www.beckershospitalreview. com/hospital-management-administration/7-factors-to-assess-thesustainability-of-a-hospital-assessing-a-hospitals-viability-its-financialsituation-and-the-severity-of-the-threats-it-faces.html

29 US Government Accountability Office. Report to Congressional Requesters: Rural hospital closures: Number and characteristics of affected hospitals and contributing factors. Washington: GAO, 2018. www.gao.gov/assets/700/694125.pdf

30 Langenbrunner JC, Wiley MM. Hospital payment mechanisms: theory and practice in transition countries. In: McKee M, Healy ] (eds). Hospitals in a changing Europe. Buckingham: Open University Press, 2002:150-76.

31 Palmer W, Appleby ], Spencer J. Rural health care: A rapid review of the impact of rurality on the costs of delivering health care. London: Nuffield Trust, 2019

32 Donnelly L. Hospitals paying locum doctors record sums of $£ 4,000$ per shift. Telegraph 2019. www.telegraph.co.uk/news/2019/10/11/ hospitals-paying-locum-doctors-record-sums-4000-per-shift

33 Sahni NR, Dalton M, Cutler DM, Birkmeyer JD, Chandra A. Surgeon specialization and operative mortality in United States: retrospective analysis. BMJ 2016:354:i3571.

34 Jollis JG, DeLong ER, Peterson ED et al. Outcome of acute myocardial infarction according to the specialty of the admitting physician. N Engl J Med1996;335:1880-7.

35 Stone VE, Mansourati MD, Poses RM, Mayer KH. Relation of physician specialty and HIV/AIDS experience to choice of guideline-recommended antiretroviral therapy. J Gen Intern Med 2001;16:360-8.

36 Ward MM, Leigh P, Fried JF. Progression of functional disability in patients with rheumatoid arthritis. Arch Intern Med 1993;15:2229-37.

37 Schmitt S, McQuillen DP, Nahass R et al. Infectious diseases specialty intervention is associated with decreased mortality and lower healthcare costs. Clin Infect Dis 2014;58:22-8.

38 Brescia AA, Patel HJ, Likosky DS et al. Volume-outcome relationships in surgical and endovascular repair of aortic dissection. Ann Thorac Surg 2019;108:1299-306.

39 Kumbhani DJ, Cannon CP, Fonarow GC et al. Association of hospital primary angioplasty volume in ST-segment elevation myocardial infarction with quality and outcomes. JAMA 2009;302:2207-13.

40 Schmidt CM, Turrini O, Parikh P et al. Effect of hospital volume, surgeon experience, and surgeon volume on patient outcomes after pancreaticoduodenectomy. A single-institution experience. Arch Surg 2010;145:634-40.

41 Woo YL, Kyrgiou M, Bryant A, Everett T, Dickinson HO. Centralisation of services for gynaecological cancer. Cochrane Database Syst Rev 2012:CD007945.

42 Watson R, Crump H, Imison C, Currie C, Gaskins M. Emergency general surgery: challenges and opportunities. London: Nuffield Trust, 2016.

43 Shahin J, Harrison DA, Rowan KM. Relation between volume and outcome for patients with severe sepsis in United Kingdom: retrospective cohort study. BMJ 2012;344:e3394.

44 Mason S, Locker T, Carter A et al. What are the organisational factors that influence waiting times in emergency departments? National Co-ordinating Centre for NHS Service Delivery and Organisation, 2006. www.netscc.ac.uk/hsdr/files/project/SDO_ FR_08-1310-049_V01.pdf

45 Donohoe MT. Comparing generalist and specialty care: discrepancies, deficiencies, and excesses. Arch Intern Med 1998;158:1596-608.

46 Smetana GW, Landon BE, Bindman AB et al. A comparison of outcomes resulting from generalist vs specialist care for a single discrete medical condition: a systematic review and methodologic critique. Arch Intern Med 2007;167:10-20.

47 Harrold LR, Field TS, Gurwitz JH. Knowledge, patterns of care, and outcomes of care for generalists and specialists. J Gen Intern Med 1999;14:499-511.

48 Lu TH, Li ST, Liang FW, Lee JC, Yin WH. When high-volume PCI operators in high-volume hospitals move to lower volume hospitals. Do they still maintain high volume and quality of outcomes? Catheter Cardiovasc Interv 2018;92:644-50.

49 Rashid M, Sperrin M, Ludman PF et al. Impact of operator volume for percutaneous coronary intervention on clinical outcomes: what do the numbers say? Eur Heart J Qual Care Clin Outcomes 2016;2:16-22.

50 Nally DM, Sørensen ], Valentelyte $G$ et al. Volume and in-hospital mortality after emergency abdominal surgery: a national population based study. BMJ Open 2019;9:e032183.

51 Natafgi N, Baloh J, Weigel P, Ullrich F, Ward MM. Surgical patient safety outcomes in critical access hospitals: how do they compare? J Rural Health 2017;33:117-26.

52. Humber N, Frecker T. Rural surgery in British Columbia: is there anybody out there? Can J Surg 2008;51:179-84.

53 Aubrey-Bassler K, Cullen RM, Simms A et al. Outcomes of deliveries by family physicians or obstetricians: a population-based cohort study using an instrumental variable. CMAJ 2015;187: 1125-32.

54 Tsugawa Y, Newhouse JP, Zaslavsky AM et al. Physician age and outcomes in elderly patients in hospital in the US: observational study. BMJ 2017;357:j1797.

55 Fulop NJ, Ramsay AIG, Hunter RM et al. Evaluation of reconfigurations of acute stroke services in different regions of England and lessons for implementation: a mixed-methods study. Health Services and Delivery Research, no 7.7. Southampton: NIHR Journals Library, 2019. 
56 Moran CG, Lecky F, Bouamra O et al. Changing the system - major trauma patients and their outcomes in the NHS (England) 200817. EClinicalMedicine 2018;2:13-21.

57 Metcalfe D, Bouamra O, Parsons NR et al. Effect of regional trauma centralization on volume, injury severity and outcomes of injured patients admitted to trauma centres. Br J Surg 2014;101: 959-64.

58 NHS Digital. Hospital Episode Statistics (HES). NHS, 2019. https:// digital.nhs.uk/data-and-information/data-tools-and-services/dataservices/hospital-episode-statistics

59 Royal College of Surgeons of England. Surgery and the NHS in numbers. London: RCS, 2014. www.rcseng.ac.uk/news-and-events/ media-centre/media-background-briefings-and-statistics/surgeryand-the-nhs-in-numbers

60 Waton S, Johal A, Heikkila K et al. National Vascular Registry: 2018 annual report. London: The Royal College of Surgeons of England, 2018.

61 Weinhold I, Gurtner S. Understanding shortages of sufficient health care in rural areas. Health Policy 2014;118:201-14.

62 Yang Y, Li J, Wu X et al. Factors influencing subspecialty choice among medical students: a systematic review and meta-analysis. BMJ Open 2019;9:e022097.

63 Trudgill N. Focus on physicians: census of consultant physicians and higher specialty trainees 2018. London: Royal College of Physicians, 2018

64 Royal College of Emergency Medicine. Essential facts regarding A\&E services. London: RCEM, 2018. www.rcem.ac.uk/docs/Policy/ England \% 20Factsheet \% 202018.pdf

65 Independent Working Time Regulations Taskforce. The implementation of the Working Time Directive, and its impact on the NHS and health professionals. Report of the Independent Working Time Regulations Taskforce to the Department of Health. London: Royal College of Surgeons of England, 2014.

66 Vaughan L, Machaqueiro Gaskins M, Imison C. The London Quality Standards: A case study in changing clinical care. London: Nuffield Trust, 2017.

67 Faculty of Intensive Care Medicine. Guidelines for the provision of intensive care services, 2nd edn. London: FICM, 2019.

68 Recruit and Retain Collaboration. Making it work. A framework for remote rural workforce stability. Storuman: Recruit and Retain Collaboration, 2019. https://rrmakingitwork.eu/wp-content/ uploads/2019/03/Making-it-Work-Framework-for-Remote-RuralWorkforce-Stability.pdf

69 Hempel S, Maggard Gibbons M et al. Rural healthcare workforce: A systematic review. VA ESP Project \#05-226. VA Healthcare, 2015. https://pdfs.semanticscholar.org/7ff4/b3f326889d2162f82d5d47f335f259abaebd.pdf

70 Dornagala A, Bala MM, Storman D et al. Factors associated with satisfaction of hospital physicians: a systematic review of European data. Int J Environ Res Public Health 2018;15:2546.

71 Imison C, Castle-Clarke S, Watson R. Reshaping the workforce to deliver the care patients need. London: Nuffield Trust, 2016.

72 Penn ML, Monks T, Pope C, Clancy M. A mixed methods study of the impact of consultant overnight working in an English emergency department. Emerg Med J 2019;36:298-302.

73 Hamilton-Fairly D, Coakley J, Moss F. Hospital at night: an organizational design that provides safer care at night. BMC Med EduC 2014:14(Suppl 1):S17.

74 Lehmann U, Dieleman M, Martineau T. Staffing remote rural areas in middle - and low-income countries: a literature review of attraction and retention. BMC Health Serv Res 2008:8:19.

75 MacQueen IT, Maggard-Gibbons M, Capra G et al. Recruiting rural healthcare providers today: a systematic review of training program success and determinants of geographic choices. J Gen Intern Med 2018:33:191-9.

76 Grobler L, Marais B], Mabunda S. Interventions for increasing the proportion of health professionals practising in rural and other underserved areas. Cochrane Database Syst Rev 2015:CD005314.
77 Bärnighausen T, Bloom DE. Financial incentives for return of service in underserved areas: a systematic review. BMC Health Serv Res 2009;9:86

78 Johnson GE, Wright FC, Foster K. The impact of rural outreach programmes on medical students' future rural intentions and working locations: a systematic review. BMC Med Educ 2018;18:196.

$79 \mathrm{NHS}$ Health Education England. New medical schools to open to train doctors of the future. Health Education England, 2018. www. hee.nhs.uk/news-blogs-events/news/new-medical-schools-opentrain-doctors-future

80 Reid W. Reforming medical education for the good of all. Health Education England, 2019. www.hee.nhs.uk/news-blogs-events/ blogs/reforming-medical-education-good-all

81 NHS. Targeted Enhanced Recruitment Scheme. NHS, 2018. www.england.nhs.uk/gp/the-best-place-to-work/starting-your-career/recruitment

82 Stewart E. A sociology of public responses to hospital change and closure. Sociol Health Illn 2019;41:1251-69.

83 Droog E, Foley C, Healy O et al. Perspectives on the underlying drivers of urgent and emergency care reconfiguration in Ireland. Int J Health Plann Manage 2018:33:364-79.

84 Rosenbach ML, Dayhoff DA. Access to care in rural America: impact of hospital closures. Health Care Financ Rev 1995;7:15-37.

85 Liu L, Brossart B, White R, Lewis S. Impact of rural hospital closures in Saskatchewan, Canada. Soc Sci Med 2001:52:1793-804.

86 Avdic D, Lundborg P, Vikström J. Mergers and birth outcomes: evidence from maternity ward closures. Berlin: Institute of Labour Economics, 2018. http://ftp.iza.org/dp11772.pdf

87 Lee DC, Carr FG, Smith TE et al. The impact of hospital closures and hospital and population characteristics on increasing emergency department volume: a geographic analysis. Popul Health Manag 2015;18:459-66.

88 Gujral K, Basu A. Impact of rural and urban hospital closures on inpatient mortality: NBER working paper no 26182. Cambridge: National Bureau of Economic Research, 2019. www.nber.org/ papers/w26182.

89 Carroll C. Impeding access or promoting efficiency? Effects of rural hospital closure on the cost and quality of care. Harvard Kennedy School working paper. Cambridge: Harvard University, 2019. https://scholar.harvard.edu/files/ccarroll/files/carroll_jmp.pdf

90 Song LD, Saghafian S. Do hospital closures improve the efficiency and quality of other hospitals? Harvard Kennedy School working paper RWP19-006. Cambridge: Harvard University, 2019. https:// scholar.harvard.edu/files/saghafian/files/hospital_closure-web.pdf

91 The Mid Staffordshire NHS Foundation Trust Public Inquiry. Report of the Mid Staffordshire NHS Foundation Trust Public Inquiry. Executive summary. London: The Stationery Office, 2013.

92 Vaughn VM, Saint S, Krein SL et al Characteristics of healthcare organisations struggling to improve quality: results from a systematic review of qualitative studies. BMJ Qual Saf 2019;28: 74-84.

93 Fulop N, Protopsaltis G, Hutchings A et al. Process and impact of mergers of NHS trusts: multicentre case study and management cost analysis. BMJ 2002;325:246

94 Ovseiko PV, Melham K, Fowler J, Buchan AM. Organisational culture and post-merger integration in an academic health centre: $a$ mixed-methods study. BMC Health Serv Res 2015;15:25.

95 Weil T. Hospital mergers: a panacea? J Health Serv Res Policy 2010;15:251-3.

96 Fulop N, Protopsaltis G, King A et al. Changing organisations: a study of the context and processes of mergers of health care providers in England. Soc Sci Med 2005;60:119-30.

97 Collins B. Changing organisations: a study of the context and processes of mergers of health care providers in England. London: King's Fund, 2015.

98 Sheppard O. £80 million spent on consultants for West London NHS could have paid for 255 nurses for a decade. MyLondon 2019. 
www.mylondon.news/news/west-london-news/nhs-hospitals-closedhealth-symptoms-16804298

99 Department of Transport. Journey time statistics. Access to services 2014. London: DoT, 2014. https://assets.publishing.service. gov.uk/government/uploads/system/uploads/attachment_data/ file/485222/jts-access-2014.pdf

100 Moriarty ], Manthorpe J, Harris ]. Recruitment and retention in adult social care services. London: King's College London, 2018. www.kcl. ac.uk/scwru/pubs/2018/reports/recruitment-and-retention-report.pdf

101 Gibson LM, Whiteley W. The differential diagnosis of suspected stroke: a systematic review. J R Coll Physicians Edinb 2013;43:114-8.

102 Hoang H, Terry D. Women's access needs in maternity care in rural Tasmania, Australia: a mixed methods study. Women and Birth 2015:27:9-14.

103 Barclay L, Kornelsen J, Longman ] et al. Reconceptualising risk: Perceptions of risk in rural and remote maternity service planning. Midwifery 2016;38:63-70.

104 Smallbone D, Kitching J, Blackburn R, Mosavi S. Anchor institutions and small firms in the UK: A review of the literature on anchor institutions and their role in developing management and leadership skills in small firms. London: UK Commission for Employment and Skills, 2015. https://assets.publishing.service.gov.uk/ government/uploads/system/uploads/attachment_data/ file/414390/Anchor_institutions_and_small_firms.pdf
105 Reed S, Göpfert A, Wood S, Allwood S, Warburton W. Building healthier communities: the role of the NHS as an anchor institution. London: The Health Foundation, 2019.

106 Wishner J, Solleveld P, Rudowitz R et al. A look at rural hospital closures and implications for access to care: three case studies. Menlo Park: Kaiser Family Foundation, 2016. http://files.kff.org/ attachment/issue-brief-a-look-at-rural-hospital-closures-and-implications-for-access-to-care.

107 Holmes GM, Slifkin RT, Randolph RK, Poley S. The effect of rural hospital closures on community economic health. Health Serv Res 2006:41:467-85.

108 Sørensen JF. The potential migration effect of rural hospital closures: a Danish case study. Scand J Public Health 2008;36:460-6.

109 Taylor MM. Rural health disparities: public health, planning and policy approaches. Cham: Springer, 2019.

Address for correspondence: Dr Louella Vaughan, The Nuffield Trust, 59 New Cavendish St, London W1G 7LP, UK. Email: louella.vaughan@nuffieldtrust.org.uk Treating tobacco dependency in the NHS

Published in 2018, this report by the Tobacco Advisory Group of the Royal College of Physicians addresses the harms and costs arising from smoking in the patients we see every day, and argues for a new approach to treating their addiction.

Download the report at: www.rcplondon.ac.uk/hidingplain-sight-treating-tobaccodependency-nhs

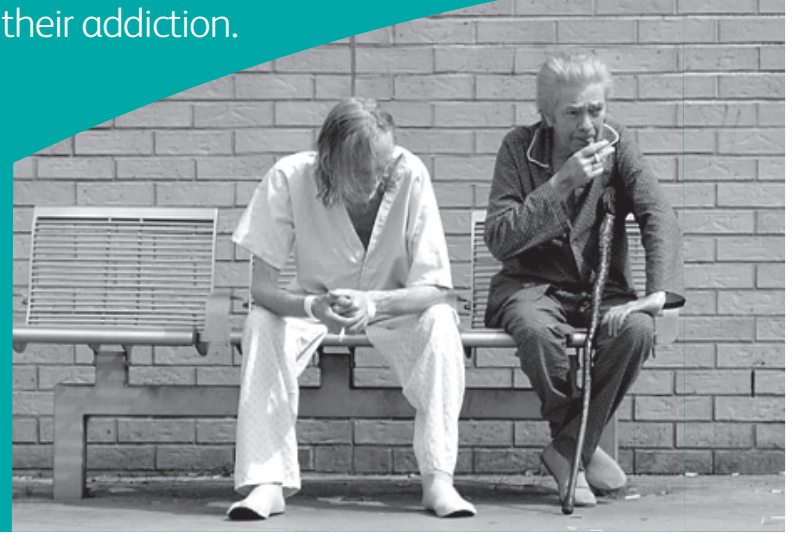

